\title{
La recuperación de la información publicada el 11-M en la prensa británica y en la española: análisis comparativo
}

\author{
María F. Sánchez Hernández \\ Raquel Rodríguez Díaz \\ Universidad Rey Juan Carlos (España)
}

\section{Resumen}

Se analiza la visión que los periódicos The Guardian y El País difundieron en los días posteriores a los atentados de Madrid del 11 de marzo de 2004, utilizando para ello dos bases de datos. En los dos días siguientes a los atentados, medios británicos y españoles ofrecieron imágenes e informaciones que reflejaban la masacre del 11-M desde distintas perspectivas. Los resultados de este trabajo nos han servido para localizar y analizar tanto imágenes como informaciones de los atentados y sus implicaciones en las elecciones generales del 14 de marzo, incluyendo al mismo tiempo los diferentes argumentos empleados por los principales partidos políticos y representantes de las fuerzas de seguridad.

Palabras clave: Atentados. Informetría. Análisis de contenido. 11-M. Madrid (España). El País. The Guardian.

\section{Abstract}

A review is offered of the coverage given by the British newspaper The Guardian and the Spanish daily El País in the days following the bombings in Madrid on $11^{\text {th }}$ March 2004 using two different databases. The next days to the bombings, both British and Spanish media gave images and information that reflected the massacre from different points of view. Through this work, we were able to locate and analyze both the images and the information about the bombings and its consequences on the Spanish general elections of 14 March, including different main viewpoints of the political parties and official security institutions.

Keywords: Bombings. Informetrics. Content analysis. 11-M. El País. The Guardian. 


\section{Introducción y objetivos}

Las bases de datos como fuentes de información se crearon con el fin de utilizar ficheros con diferentes aplicaciones. Evitan la redundancia de la información que almacenan, establecen de forma explícita las relaciones entre los datos y facilitan accesos múltiples que permiten compartir información al mismo tiempo que aseguran la protección de la que en ellas se conserva, respecto a su seguridad, integridad y confidencialidad.

Desde el inicio de nuestro trabajo hemos relacionado los principios y fundamentos de la ciencia de la documentación con los de la ciencia de la información, sintetizando los medios materiales en orden a los objetivos documentales e informativos y siguiendo una "cadena de operaciones organizadas". Por ello, se han empleado como herramienta indispensable en el análisis de contenido dos bases de datos diferentes, Lexis Nexis y File Maker, a través de las cuales hemos realizado un análisis de contenido en un diario generalista nacional (El País) y otro internacional (The Guardian). De esta manera, hemos comparado y conseguido rápida y eficazmente toda la información publicada en los dos días posteriores a los atentados del 11-M, realizando un análisis que perseguía objetivos distintos con cada una de las bases de datos y periódicos.

La principal justificación por la que se eligió un diario internacional era la de contemplar la visión y argumentación de los atentados que difundían los medios de comunicación extranjeros; y particularmente se seleccionó como muestra para esta investigación The Guardian por ser uno de los periódicos de mayor difusión en el Reino Unido, y de referencia en este país. Un estudio más amplio de la prensa de referencia anglosajona (diarios de Reino Unido y Estados Unidos) sobre el 11 de marzo de 2004 se puede consultar en Sampedro et al. (2004).

Coincidiendo con otros medios británicos, The Guardian no solo difundió detalles de la tragedia: también pasó a analizar las repercusiones políticas que los atentados tendrían en las elecciones generales convocadas para el 14 de marzo. A este respecto, es mucha la bibliografía que se ha publicado y que analiza la situación de diferentes ángulos y posiciones (Álvarez de Toledo, 2004; Michavila, 2005; Rodríguez, 2006; Reinares y Elorza, 2004; Santamaría, 2004; Uriarte, 2004). Gracias a la utilización de la base de datos electrónica Lexis Nexis pudimos combinar en las búsquedas los descriptores que estimábamos más pertinentes bajo distintos parámetros, obteniendo como resultados, de forma rápida y en bloque, los textos completos que se habían publicado en la prensa y que coincidían con nuestra solicitud de información.

En el ámbito nacional se escogió El País por ser uno de los principales diarios en España. Respecto al tratamiento empleado, nuestro objetivo primordial fue analizar las imágenes que se publicaron en este medio de comunicación. Para ello, rea- 
lizamos un análisis de más de 100 noticias publicadas tras los primeros días de la tragedia (12 y 13 de marzo); posteriormente procedimos a clasificarlas manualmente para tener una información más completa del material seleccionado y poderlo organizar adecuadamente.

Una vez obtenida la información publicada relativa a los atentados, buscamos conseguir tres objetivos: 1) analizar y clasificar de manera sistemática la información e imágenes, utilizando para ello dos bases de datos; 2) conocer parte de la visión internacional de los acontecimientos por medio de un periódico británico, analizando los argumentos empleados y sus principales enunciadores; 3 ) conocer parte de la visión nacional de los acontecimientos, reflejada en las noticias e imágenes publicadas.

\section{Metodología}

Las dos bases de datos mencionadas se han empleado con funciones diferentes ya que perseguían objetivos de análisis de contenido distintos, pero sin duda complementarios. En el diario británico, el principal de ellos residía en conocer cuáles fueron las fuentes informativas y los argumentos que se mantuvieron sobre la autoría de los atentados del 11-M. Para ello, se hizo una diferenciación entre los tipos de fuentes informativas que figuraban en primer y en segundo lugar en las noticias, al igual que los tipos de argumentación respecto a la responsabilidad de los hechos. Desde una perspectiva metodológica existen varios puntos a tener en cuenta, ya que estamos hablando de prensa internacional, con el consiguiente problema que supone una recuperación rápida y completa del seguimiento de las noticias desde España. Por este motivo, consideramos oportuno emplear la base de datos Lexis Nexis, que permite utilizar descriptores y palabras clave (en el idioma de origen del medio) que acotan las búsquedas de información por artículos que los contengan. Es una base de datos especializada en prensa internacional, con información de los diarios de referencia del mundo, actualizada diariamente.

Esta herramienta es muy útil ya que, incluso en tiempo real, ofrece a texto completo un gran índice de diarios, entre ellos The Guardian. Dicha base de datos se emplea con mucha frecuencia en aquellas investigaciones relativas a medios de comunicación en las que el análisis de contenido resulta imprescindible. Para realizar esta trabajo accedimos a Lexis Nexis a través de la Biblioteca de la Universidad Rey Juan Carlos, que cuenta con esta base de datos como recurso electrónico de texto; en este caso, no quedan recogidas las fotografías ni ningún otro elemento infográfico publicado en la versión impresa. Pese a ello, consideramos igualmente rentable el uso de la base de datos para el desarrollo del trabajo, complementado con el de las imágenes de El País.

Las búsquedas que se hicieron a través de Lexis Nexis abarcaron los géneros de información y opinión publicados los días 12 y 13 de marzo de 2004

Scire. 11 : 2 (sep.-dic. 2005) 187-196. ISSN 1135-3761. 
(inmediatamente después de los atentados y antes de las elecciones). A esta primera muestra se aplicó un filtro de artículos para descartar aquellos que no mantenían relación con los hechos señalados, como por ejemplo los vinculados a deportes. Las unidades de estudio (los textos) fueron identificadas con la búsqueda de los siguientes términos: España y terrorismo o Al Qaeda o ETA o ataques o elecciones o protestas o Iraq o votantes o manifestaciones. La búsqueda en inglés se correspondió con: Spain and Terrorism or Al Qaeda (o Qaida) or ETA or attacks or elections or protest or Iraq or voter or demonstrations. Spain y terrorism fueron dos términos imprescindibles en la búsqueda.

En paralelo se desarrolló un manual o ficha de codificación que recogiese los principales objetivos de la investigación acerca de la autoría de la masacre del 11-M, es decir, fuentes informativas o actores y principales argumentos sostenidos.

Para el análisis de The Guardian, se realizó una distinción entre las fuentes informativas (y los argumentos que sostenían sobre los autores de los atentados) que aparecían en primer y en segundo lugar en el artículo, entendiendo por lugar la prioridad o situación que ocupaban en la información, ya que, en las propias técnicas del desarrollo periodístico de pirámide invertida, los hechos informativos más relevantes ocupan los primeros párrafos de las noticias. De modo que en la medida en que la información se desarrolla en diferentes párrafos aparecen otras fuentes o enunciadores con los mismos u otros argumentos.

Para completar este estudio, hemos incorporado el análisis de las imágenes ofrecidas en la prensa española generalista, recurriendo al diario El País, que al igual que el resto de periódicos publicó fotografías en blanco y negro para las "situaciones" más "duras" y, en cambio, para las más "soportables" empleaban el color (Sánchez y Hurtado, 2004).

Finalizada esta fase del trabajo y agrupada por temas toda la documentación gráfica vaciada, el siguiente paso fue el diseño de una base de datos utilizando el programa File Maker, con el fin de localizar las imágenes que ilustraban las noticias. Los campos de la ficha fueron los siguientes: fecha de edición, titular, fuente de información, sección y/o suplemento, página, autor, extensión, ilustración y resumen.

Para lograr una recuperación eficaz de la información tratada, se elaboró un tesauro con más de 200 términos (descriptores, no descriptores y palabras clave), estructurado en cuatro partes: índice jerárquico, índice conceptual, índice sistemático global y por último índice kwic. Gracias a este instrumento y a la base de datos diseñada se pudo recuperar e identificar, de un modo más rápido, las fotografías publicadas en el periódico. 


\section{Resultados y conclusiones}

El número de artículos que se publicaron en el diario británico, con la inclusión de los descriptores mencionados, fue de 23. De entre ellos, solo nos hemos centrado en observar las informaciones que hablaban de la autoría de los hechos en primer y segundo lugar, ya que este era un elemento que podría diferenciar a The Guardian (por ser extranjero) de El País. Los resultados, reflejados en todos los gráficos que figuran en este artículo, relativos a las fuentes información y la responsabilidad de los hechos, demuestran que en este medio ya se estaban recogiendo informaciones que hacían alusión a Al Qaeda como principal sospechosa de los atentados, según declararon las fuentes de información internacional (policía internacional, Gobiernos de la UE, medios de comunicación internacional, etcétera). Pese a ello, se observa en el gráfico 1 cómo las principales fuentes informativas (primer enunciador) que ofrecían declaraciones fueron "el Gobierno en general" y "Ángel Acebes", empleando como principales argumentos (primer lugar) de implicación en la autoría de los atentados a "ETA" y a "ETA como primera vía y como segunda Al Qaeda", además de reflejar las muestras de "solidaridad" de los ciudadanos (véase gráfico 2).

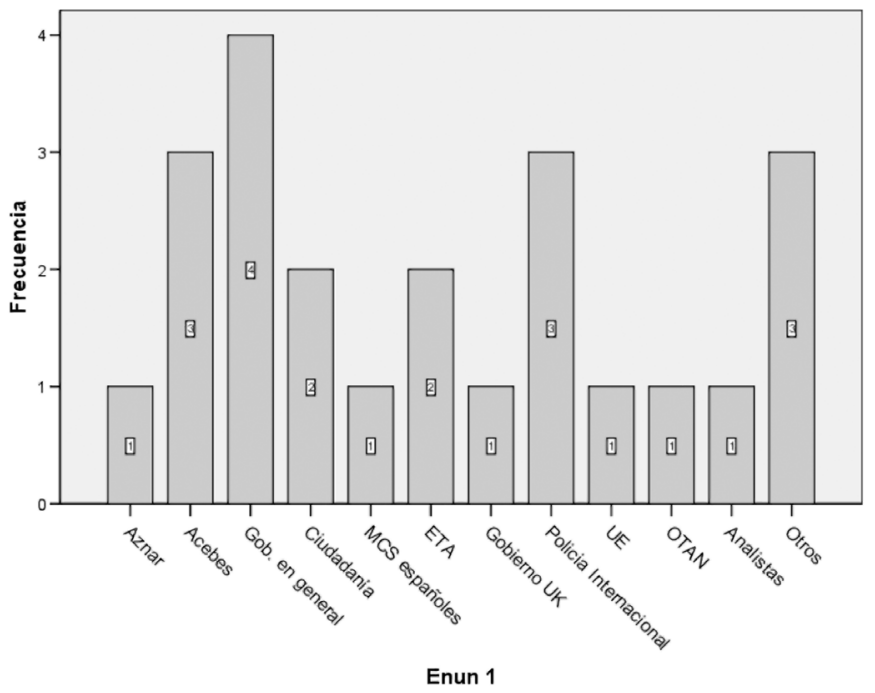

Gráfico 1. Fuente informativa, primer enunciador

De igual modo, en los gráficos 3 y 4 se analiza como segundos enunciadores o fuentes informativas a la "ciudadanía" y "Arnaldo Otegui" con argumentos de autoría vinculados, más que a ninguna otra de las posibilidades, a que "no es ETA

Scire. 11 : 2 (sep.-dic. 2005) 187-196. ISSN 1135-3761. 


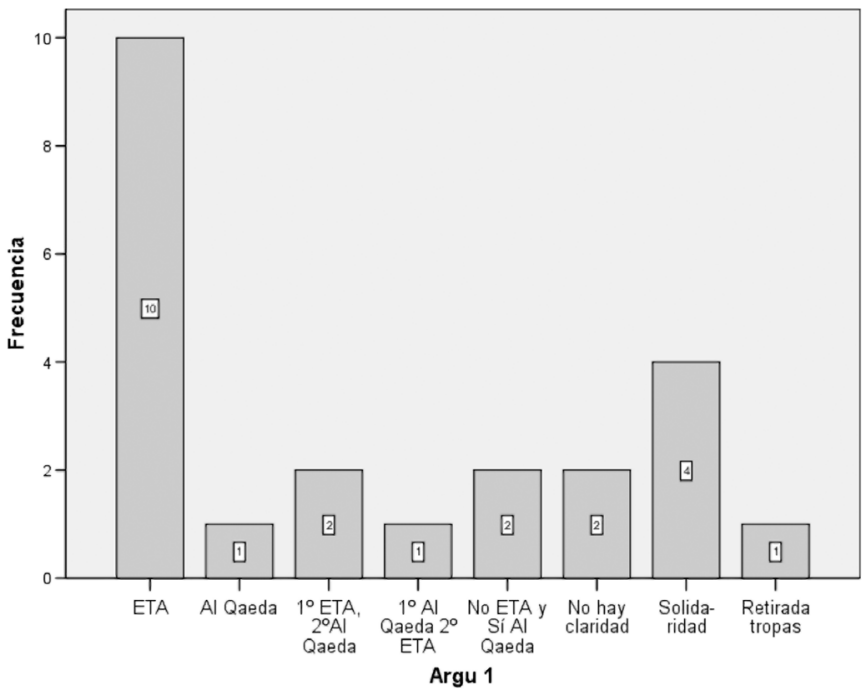

Gráfico 2. Argumentos 1 sobre la autoría de los atentados

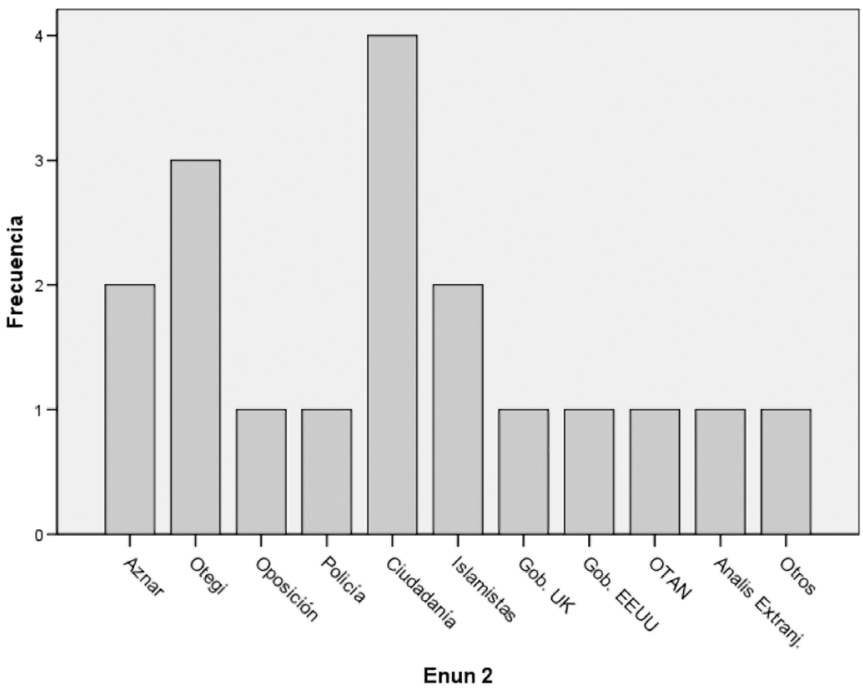

Gráfico 3. Fuente informativa, segundo enunciador

y sí Al Qaeda", seguido de "ETA” y "Al Qaeda” además de la propia expresión de la "solidaridad". 


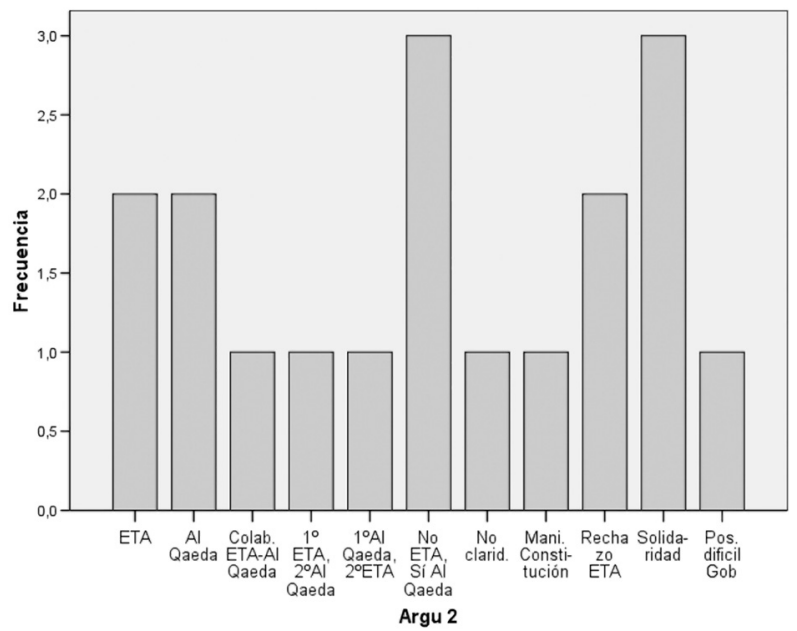

Gráfico 4. Argumentos 2 sobre la autoría de los atentados

En los gráficos 3 y 4 se contempla la fuerte presencia de "ETA" y "Al Qaeda" como autoras de los hechos, reflejando con ello la confusión que se vivió en un primer momento. Resulta aún más interesante para este trabajo observar en los gráficos 5 y 6 cómo se descarta la autoría de "ETA" el mismo día 13 de marzo, e in-

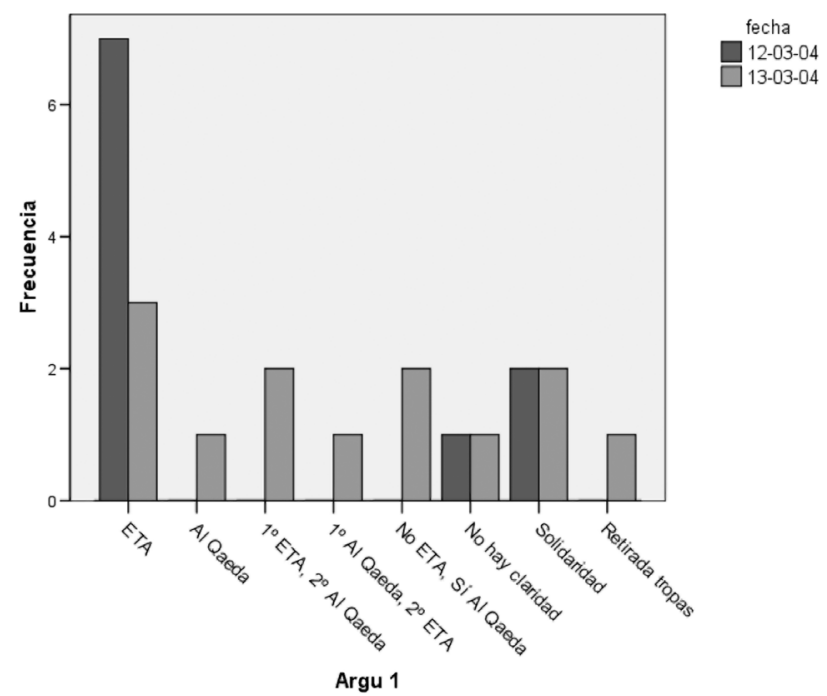

Gráfico 5. Argumentos sobre la autoría de los hechos (primer lugar)

Scire. 11 : 2 (sep.-dic. 2005) 187-196. ISSN 1135-3761. 
cluso ya el día 12, según reflejan las cifras del gráfico 6. Además, The Guardian también publicaba la confirmación de que había sido "Al Qaeda" y no ninguna otra banda terrorista la autora de los atentados, según queda reflejado por medio de los distintos argumentos empleados en segundo lugar.

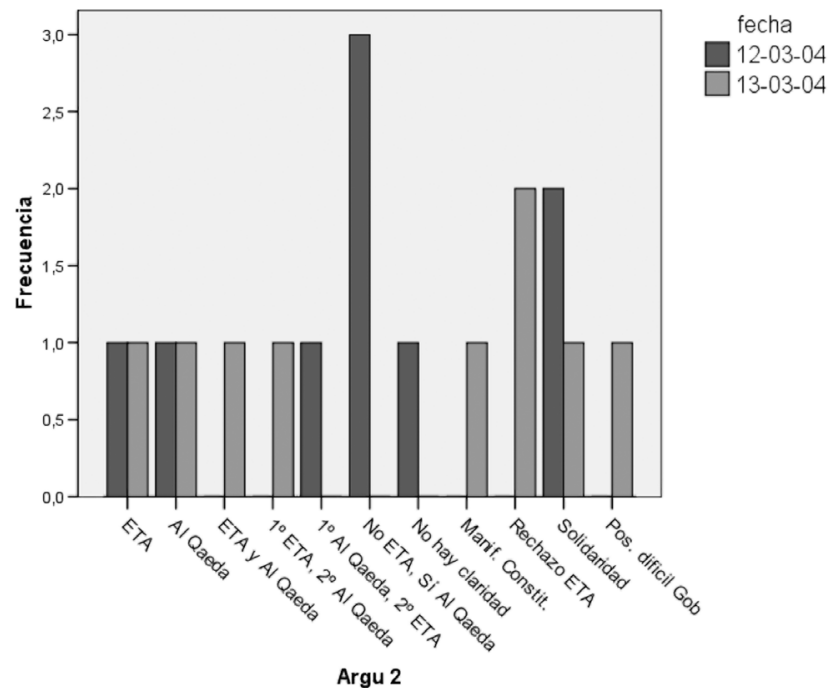

Gráfico 6. Argumentos sobre la autoría de los hechos (segundo lugar)

Para valorar la temática de las imágenes publicadas en el diario El País, hemos agrupado los descriptores que representan los contenidos más frecuentes de las ilustraciones en tres grupos de familias, como se puede observar en los siguientes gráficos:

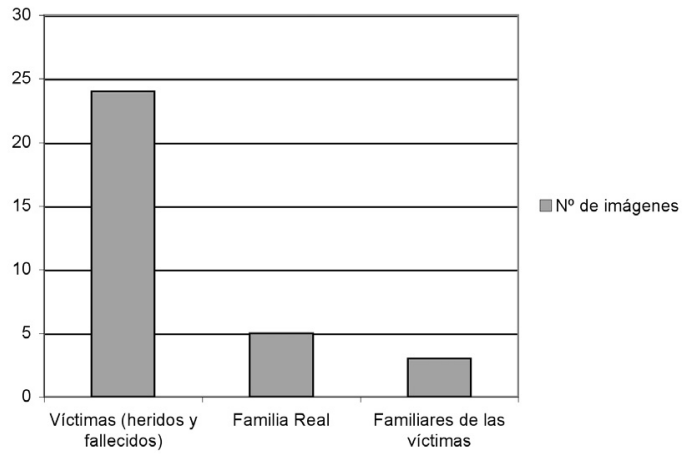

Gráfico 7. Grupo de descriptores 1

Scire. 11 : 2 (sep.-dic. 2005) 187-196. ISSN 1135-3761. 


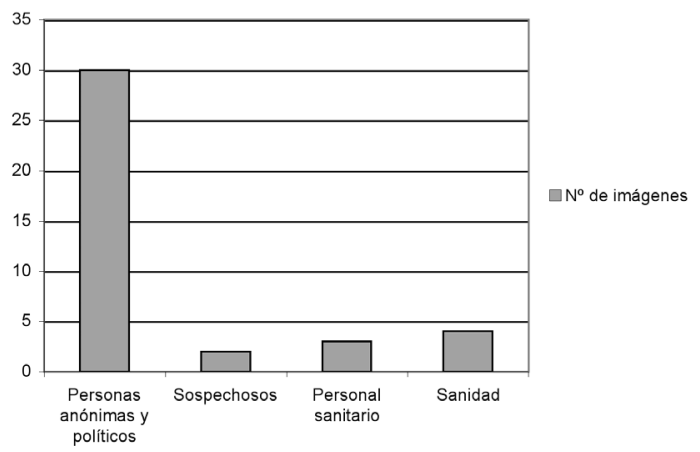

Gráfico 8. Grupo de descriptores 2

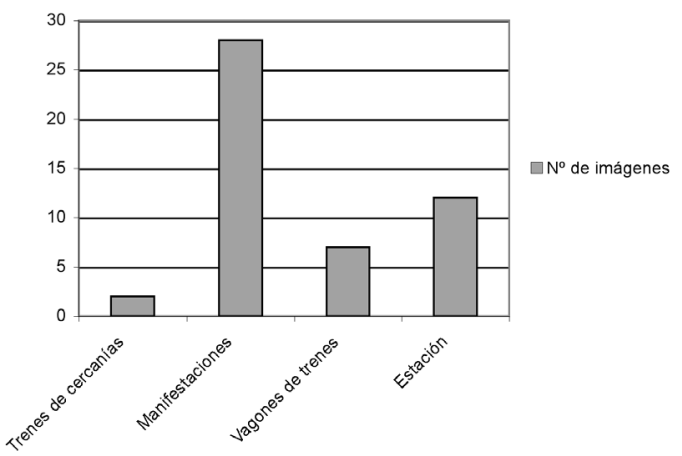

Gráfico 9. Grupo de descriptores 3

Con los resultados obtenidos en el análisis de El País mostramos que, coincidiendo con los descriptores de "víctimas y manifestaciones", se han publicado un mayor número de noticias aunque no de imágenes, y con menos ilustraciones está el grupo correspondiente a "personal sanitario, sanidad, explosiones y familia real"; por último, señalamos que se difundieron más noticias que imágenes propias de los sospechosos.

Los resultados ofrecidos reflejan o ponen en evidencia la utilidad del uso de las distintas bases de datos para recuperar y ayudar a analizar, desde diferentes perspectivas, informaciones de difícil acceso o localización, al mismo tiempo que permiten la reutilización los documentos iniciales. 


\section{Referencias}

Álvarez de Toledo, Consuelo (2004). Cuatro días de marzo: la verdad sobre el 11-M. Madrid: Planeta, 2004.

Azurmendi, Ana (2005). Sobre el 11-M: comunicando el terror y la solidaridad. // El poder de comunicación como propuesta. URL: <http: www. Infodialogue.org./comunicaciones.php>. Consultado: 2005-04-05.

Michavila, Narciso (2005). Guerra, terrorismo y elecciones: incidencia electoral de los atentados islamistas de Madrid, Documento de trabajo $n^{\circ} 13$. Madrid: Real Instituto Elcano, 13 de marzo de 2005.

Lago, Ignacio; Montero, José Ramón (2004). Los mecanismos del cambio electoral. Del 11-M al 14-M. // Claves de la Razón Práctica. 149 (2004) 36-44.

Reinares, Fernando; Elorza, Antonio (2004). El nuevo terrorismo islamista: del 11-S al 11-M. Madrid: Temas de Hoy, 2004.

Rodríguez Díaz, Raquel (2006). Miedo post-11 y terrorismo en España. // Recerca. Universitat Jaume I, Castellón (en prensa).

Sánchez Hernández, María F.; Hurtado Guapo, Ma Antonia (2004). Estudio de imágenes del 11-M a través de la prensa regional y nacional: recogida y análisis de datos. // III Jornadas sobre Imagen, Cultura y Tecnología. Madrid: Universidad Carlos III.

Santamaría, Julián (2004). El azar y el contexto. Las elecciones generales de 2004. // Claves de la Razón Práctica. 146 (octubre de 2004) 28-43.

Sampedro, Víctor; Rodríguez, Raquel; García de Madariaga, José Ma; Tucho, Fernando (2004). El 11-M y el 14-M en la prensa de referencia anglosajona (Estados Unidos y Reino Unido). // Congreso Internacional de Comunicación. Pamplona: Universidad de Navarra, 2004. URL: <http://www.unav.es/fcom/cicom/pdf/g7.cobertura_teoria_ radiotv/sampedro\%20y\%20otros\%20anglosajona.pdf>. Consultado: 2005-03-30.

Torres Fernández, Pablo; Minaya Ropero, Francisco; Benito Sacristán, Pilar (2004). 11-M: homenaje a las víctimas. Barcelona: Martínez Roca.

Uriarte, Edurne (2004). Terrorismo y democracia tras el 11-M, Madrid: Espasa-Calpe, 2004. 